\title{
Alternatives or syntactic negation? Adults' and children's preferences for constructing counterfactual possibilities
}

\author{
Jesica Gómez-Sánchez ${ }^{1} \cdot$ Sergio Moreno-Ríos ${ }^{1}\left[\right.$ Caren Frosch $^{2}$
}

Accepted: 29 October 2021

(c) The Author(s) 2021

\begin{abstract}
Reasoning with counterfactuals such as "if his sister had entered silently, the child would have been awake", requires considering what is conjectured ("his sister entered silently") and what is the counterfactual possibility ("his sister did not enter silently"). In two experiments, we test how both adults (Study 1) and children from 8 to 12 years (Study 2) construct counterfactual possibilities about the cause of an effect ("the child was awake because..."). We test specifically whether people construct the counterfactual possibility by recovering alternatives, for example, "the alarm clock sounded" or by using the syntactic negation using propositional symbols ("his sister did not enter silently"). Moreover, as children show difficulty in thinking with abstract contents, we test whether they construct the counterfactual possibility more readily by recovering concrete alternatives ("the alarm clock sounded") rather than abstract alternatives ("he had trouble sleeping"). Results showed that children, as well as adults, recovered the alternative as the cause of the effect rather than the negation. Moreover, children, unlike adults, created the counterfactual possibility more frequently by recovering concrete situations rather than abstract situations.
\end{abstract}

Keywords Counterfactual reasoning $\cdot$ Negation $\cdot$ Concreteness $\cdot$ Epistemic status $\cdot$ Alternatives $\cdot$ Mental models

Counterfactual thinking requires thinking about false possibilities, that is, what could have happened in a different situation. Imagine a situation in which a friend, Eva, studied psychology but, what if Eva had chosen to study art instead of psychology?

Counterfactuals such as

(1) "If Eva had studied art, she would have worked at the Louvre Museum"

are conditional expressions that establish a hypothetical relation between cause and effect. Many studies have shown that, as the mental model theory proposes (Johnson-Laird \& Byrne, 1991), understanding a counterfactual makes us think about two situations. One of them is the situation that corresponds to the counterfactual conjecture ("Eva studied

Jesica Gómez-Sánchez

gomezjs@ugr.es

1 Departamento de Psicología Evolutiva y de la Educación, Universidad de Granada, Granada, Spain

2 Department of Neuroscience, Psychology and Behaviour, School of Psychology, University of Leicester, Leicester, UK art and worked at the Louvre Museum"; (A, B)) and the other, corresponding to the negation of both terms, refers to the real or presupposed fact ("Eva did not study art and did not work at the Louvre Museum"; (Not-A, Not-B)) (Byrne, 2016; Byrne, 2017).

[Conjectured] Eva studied art (A) Worked at the L.M. (B)

[Presupposed-fact] Eva did not study art $(\neg \mathrm{A})$ Did not work at the L.M. $(\neg \mathrm{B})$

However, the mental model theory also establishes that we do not just have to consider both possibilities, but also need to keep track of their epistemic status by codifying it as labels (see [conjectured] and [presupposed-fact] labels above) (Johnson-Laird \& Byrne, 2002). This means recognising which one of them is the real possibility and which one the conjectured possibility. Keeping track of the epistemic status is a difficult aspect of thinking counterfactually, as demonstrated by studies with children (Gómez-Sánchez et al., 2020) as well as with adults (Ruiz-Ballesteros \& Moreno-Ríos, 2017).

Counterfactuals such as (1) require negating the antecedent in order to create the counterfactual possibility: "Eva did not study art" and, as far as we are aware, it is not known how people construct it. Is it possible that people would 
consider "Eva studied psychology" instead of "Eva did not study art". In both cases they are counterfactual possibilities (presupposed facts), one with an explicit negation and the other with an alternative.

Thus, the main aim of this paper is to establish, how during counterfactual thinking people construct that negation of the conjectured possibility to create the presupposed fact. Do they construct the negation of the antecedent using propositional symbols ("she did not study art") or do they represent an alternative fact (e.g. "she studied psychology")? Do children construct it in the same way as adults? Does it make a difference having a concrete ("she studied art") or an abstract ("she studied a career") situation? These questions arise from results of previous studies showing developmental differences in counterfactual reasoning, construction of the negation and abstract thinking. In this paper we try to disentangle these questions focusing on the role of alternatives and negation.

First, we briefly summarize relevant findings on the development of counterfactual reasoning and how people understand counterfactuals. Following this summary, we review the effect of negation found in some recent studies with inferences (Byrne, 2017; Espino \& Byrne, 2018; Moreno-Ríos \& Byrne, 2018), and how reasoning with negation changes during development (Markovits, 2013; Markovits \& Lortie-Forgues, 2011). We then outline the task that allows us to test our predictions about the effect of each kind of situation (concrete and abstract) on creating counterfactual possibilities. Furthermore, we examine the ability to reason with counterfactuals in adults and children, as well as their ability to distinguish real and conjectured possibilities. We report the results of two experiments, one with adults (Study 1) and another with children (Study 2). Finally, we discuss the findings in relation to previous literature.

\section{The Development of Counterfactual Thinking}

Previous results may question that children construct the counterfactual possibility (the negation of the suppositional possibility) in the same way as adults (e.g. Rafetseder et al., 2013). There is no agreement on when counterfactual thinking is fully developed in children, with some research finding this ability in school children (Gómez-Sánchez et al., 2020; McCormack et al., 2018; Nyhout et al., 2019) and others suggesting that even pre-schoolers are able to reason counterfactually in the same way as adults do (Guajardo et al., 2009; Nyhout \& Ganea, 2019; RoldánTapia et al., 2017). However, there is no clear explanation about the differences found between studies that find evidence for counterfactual thinking in early childhood and those that report it in later childhood. A number of factors could be responsible for these differences, such as demands on executive functions (Beck et al., 2009; Beck \& Riggs, 2014), the structure, clarity and difficulty of the task or whether the task implies physical rather than agents as causes (McCormack et al., 2018; Nyhout et al., 2019; Nyhout \& Ganea, 2019). Differences found in counterfactual thinking abilities could also be related to differences in the conceptualisation of counterfactual thinking, such as how broad or narrow the author's view of counterfactuals is (e.g. whether it includes hypothetical future, timeless conditionals or just alternatives to past events) (Beck \& Riggs, 2014; Buchsbaum et al., 2012; Rafetseder et al., 2010; Weisberg \& Gopnik, 2013) or a misunderstanding in what the task is measuring (Rafetseder et al., 2010, 2013). Another factor that has been found to cause children's difficulty in reasoning with counterfactuals could relate to the ability to codify correctly the epistemic status, that is keeping track of which possibility is real and which one is conjectured (Gómez-Sánchez et al., 2020). Due to the high working memory load, they could lose the mental footnotes about which situation is the real one and which the conjectured one. Consequently, they could still access the two models but not their mental footnotes. Although to a lesser degree, in some demanding tasks even adults lose track of the epistemic status in counterfactual reasoning (Ruiz-Ballesteros \& Moreno-Ríos, 2017).

The development of counterfactual thinking could be also related to the consideration of alternatives (MorenoRios \& García-Madruga, 2002; Rasga et al., 2016). The ability to consider alternatives as well as working memory capacity increase with age (Barrouillet et al., 2009; Santamaría et al., 2013). Counterfactual reasoning requires the consideration of false alternatives, having to temporarily inhibit our knowledge and imagine an alternative situation was true (Byrne, 2016; Rafetseder et al., 2010). Therefore, due to developmental issues we expect a developmental trend in children's ability to think counterfactually, and particularly, in their ability to keep track of epistemic status. As we explained before, the mental footnotes are easily forgotten and these are essential for answering the epistemic question correctly (i.e., what is real and what conjectured). Nevertheless, when the mental footnotes are forgotten, the mental model remains, enabling a correct answer to the inferential question.

As we have seen, to create the counterfactual possibility from (1) it is necessary to negate the antecedent ("she did not study art"). Hence, the construction of negation in counterfactuals could be another key element in the explanation of the difficulty children have with counterfactuals. 


\section{Reasoning with Negation}

Developmental differences need to be understood within the context of the challenges that arise for all people when reasoning with negation. People usually represent a sentence such as "there is not a circle" as "not-circle", that is, the representation of negation may include symbolic annotations to capture negation such as "not" (e.g., Byrne \& Johnson-Laird, 2009; Johnson-Laird \& Byrne, 2002; Khemlani et al., 2012, 2014; Moreno-Ríos \& Byrne, 2018). However, in a situation in which there is an alternative such as a triangle, the negation of "there is not a circle" leads people to think about the "triangle". That is, when there is a potential alternative, it is easier to represent the negation by recovering that alternative. This happens in binary contexts such as "there is not a light figure". In these cases it is easier to represent the negation by thinking of the alternative ("dark figure") than by thinking of the negation in an abstract way ("not light figure") as it only has one potential alternative: its antonym (Espino \& Byrne, 2018; Mayo et al., 2004).

Similarly, Espino and Byrne (2018) found an inferential effect in binary contexts that they called "inference-to-alternates": a tendency to draw affirmative conclusions that refer to an alternate even from a negative minor premise. In our study, we predict a similar effect but related to the recovery of the cause responsible for the effect (see Study 1). In more complex situations, where the negation refers to more than one possibility (e.g. circle, triangle and square) people can use the symbolic annotations to economise the process (Espino \& Byrne, 2018; Orenes et al., 2014).

This brings us on to the developmental differences in the ability to use negations. Previous studies have shown that schoolchildren use concrete cases for negating the antecedent and that the ability to create more abstract negations develops in adolescence and adulthood (Markovits, 2013; Markovits \& Lortie-Forgues, 2011). Thus, schoolchildren would find difficult to create abstract negation (not-circles), thinking instead about concrete categories (triangles). However, adolescents and adults can construct the negation of the antecedent in an abstract way, thinking in not-A abstract cases (not-circles) (Markovits \& Lortie-Forgues, 2011). In this paper we test the effect of such concreteness in the construction of counterfactual possibilities from the negation of the supposition.

Frequently, negation is not explicit but included in the context. That is what happens in the case of counterexamples.

\section{Counterexamples and Negation}

A conditional such as "If Daniella makes a noise, Charles is awake" (If A, then B) expresses a relation between a cause (A; making a noise) and an effect (B; being awake).
However, this causal relation can be different if there are counterexamples for it. There are two kinds of counterexamples (see, Cummins, 1995; De Neys \& Everaerts, 2008):

a) Alternatives (Not-A, B) which are causes, different from the original one (e.g., an alarm clock ringing), that are capable of producing the same effect cited in the relation (Charles is awake). That is, Charles may be awake (B) even if Daniella does not make a noise (not-A).

b) Disablers (A, Not-B) which prevent the effect from occurring (Charles being awake) despite the presence of the cause (Daniella makes a noise), because something breaks the causal relation (e.g., Charles wears earplugs). That is, Daniella making a noise (A) does not cause Charles to be awake (Not-B).

As we have seen, counterfactual conditionals such as "If Daniella had made a noise, Charles would have been awake" tell us that something different to what is said ("Daniella made noise and Charles was awake"; AB) actually happened ("Daniella did not make noise and Charles was not awake"; Not-A Not-B).

The mental model theory suggests that these possibilities are represented as a mental model of reality: an iconic representation of a possibility as the image of a girl making a noise and a boy awakes. As we have mentioned previously, the mental model theory also establishes that there is a codification of their epistemic status as mental footnotes. However, people tend to easily forget these mental footnotes which causes frequent errors in deduction (see Johnson-Laird, 2006; Johnson-Laird \& Byrne, 2002). These mental models can also contain abstract features such as negations (the girl not making a noise or "it is false that the girl made a noise"), and obligation or belief (Bucciarelli \& Johnson-Laird, 2005; Vargas et al., 2011). Thinking counterfactually requires negating the antecedent to create the counterfactual possibility (presupposed fact: "Daniella did not make a noise"), but how do people think about negation in counterfactual thinking? the main purpose of this paper is to shed light on this issue.

As we have seen in the previous section, negation shows differences depending on different aspects such as the age of the child, the kind of content (e.g. concrete or abstract) or the nature of the counterexamples. Therefore, in a counterfactual conditional, if the counterexample is an alternative then the negation will correspond to an element from the story (the alternative). However, if the counterexample is a disabler then the negation will not correspond to any element from the story. Consider the next two stories to explain how negation induced by a counterfactual differs with both types of counterexample: 


\section{Alternative story:}

(2) A child was awake because his alarm clock had just sounded. His sister went into his bedroom to take a toy. Later, the police officer said: "If his sister had entered silently, the child would have been awake"

\section{Disabler story:}

(3) A girl was on the beach playing with a bucket. Her bucket was broken and had a hole in the bottom. Later, the police officer said: "If the girl had poured water into her bucket, the bucket would have been empty".

In alternatives stories such as (2), the negation of the antecedent "if his sister had entered silently" can be made either by a) constructing a syntactic negation using propositional symbols such as "not" ("the sister did not enter silently") or b) discarding the mentioned action and taking the alternative action explicitly mentioned in the story ("the alarm clock sounded"). However, in disabler stories such as (3) the negation of the antecedent ("the girl did not pour water into her bucket") has no alternative explicit negation to recover from the story. Hence, for disablers the negation has to be made in a more abstract way, being forced to use the symbolic annotations ("she did not pour water").

Nevertheless, even with the presence of an explicit negation in alternative stories, it is possible to have a concrete (e.g., an alarm clock) or an abstract alternative (e.g., having trouble sleeping) (see the materials section for more information). We compare these two types of alternatives in order to test our main aim: whether children, but not adults, recover as cause of the effect (why the child is awake) a concrete alternative (the alarm clock) more than an abstract one (trouble sleeping; Markovits \& Lortie-Forgues, 2011). However, since there is no explicit alternative that can be used to negate the antecedent in disabler stories, these stories will be used as a control. Consequently, introducing a concrete (e.g. pick white stones up) or an abstract action (e.g. be occupied) in disabler stories should not have any effect since those actions do not correspond to the negation of the antecedent. That is, in disabler stories the concreteness of the cause remains constant (the hole in the bucket) unlike alternative stories.

One of the most common difficulties in comparing cognitive abilities between children and adults is that results of the studies are usually obtained with different tasks, and it is not clear to what extent differences found can be due to the tasks (Royzman et al., 2003). Therefore, our experiments used the same task to examine the ability to reason counterfactually and to keep track of the epistemic status. This task also allows us to test our main aim: how people construct the counterfactual possibility. More specifically, whether people construct the negation of the antecedent in counterfactuals either using an alternative (e.g. "the alarm clock sounded") or using the abstract negation by itself with symbolic annotations (e.g. "the sister did not enter silently"). Moreover, we also test whether the concreteness of the situation (concrete vs. abstract) has an effect depending on the kind of counterexample (alternative vs. disabler). In general, we predict that adults, as well as children, will negate the antecedent by recovering the alternative or the disabler instead of using symbolic annotations ("not"). Moreover, we predict an effect of concreteness for children with alternatives resulting in the recovery of the concrete alternative ("alarm clock") more than the abstract one ("trouble sleeping") to create the counterfactual situation ("his sister did not enter silently").

\section{Study 1 - Adults}

We test how adults construct counterfactual possibilities depending on the kind of counterexample (alternative vs. disabler) and the concreteness (concrete vs. abstract) of the counterexample. In Study 2 we examine whether there are differences between adults' and children's construction of counterfactual possibilities. Espino and Byrne (2018) showed that people tend to make affirmative inferences from negative premises in binary context (e.g., to act vs. not to act). The effect was called "inference-to-alternatives". We predict a similar effect with the negation of causal antecedents in counterfactual conditionals. The comprehension of counterfactuals requires a person to consider the negation of the antecedents. If people represent negation in stories by thinking about an alternative possibility instead of negating the antecedent, then we expect participants asked about the cause to explain the consequence, to create the counterfactual possibility by recovering the alternative possibility. This means that participants will recover the alternative possibility to explain the consequence (from here "predicted cause"; e.g. the alternative or the disabler provided in the story) instead of the syntactic negation of the antecedent using propositional symbols ("not") for all counterexamples types.

In the study we present alternative and disabler stories about causal events that lead to a consequence. Participants have to identify the causal event for that consequence. Alternatives stories, unlike disabler stories, provide an alternative situation that corresponds to the syntactic negation of the antecedent which causes the same consequence. However, disablers do not provide an explicit situation different from "the girl did not pour water" that corresponds to it (see Figures 1a and 1b). As concreteness only impacts on alternatives but not on disablers, recovering a concrete negation should be easier than recovering an abstract negation in alternative stories but not in control disablers stories. Nevertheless, due to adults' ability in thinking with abstract 
Fig. 1 a Causes in the alternative stories that can lead to the response, taking as example the alternative story about the child who is awake: "If his sister had entered silently, the child would have been..."b Causes in the control disabler stories that can lead to the response, taking as example the disabler story about the empty bucket "If the girl had poured water into her bucket, the bucket would have been ...". a

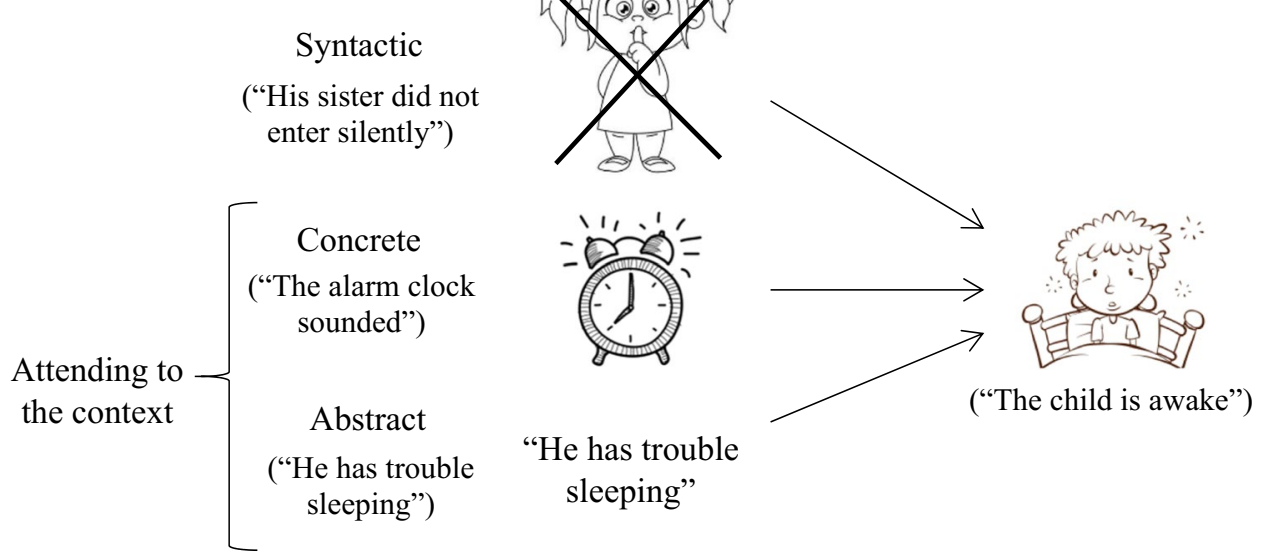

negation we do not predict significant differences in contrast to our expectations in relation to children.

Therefore, we summarize our prediction as follow:

1- If the concreteness has an impact on how people think counterfactually and also has a relation with the kind of counterexamples (alternatives and disablers), then we would expect more responses referring to the predicted cause with concrete situations than with abstract situations in alternative stories.

2- Nevertheless, we do not expect to find differences in disabler stories (that act as a control for the alternative stories), because the manipulation of the concreteness does not correspond to an alternative cause (see the materials section and Figures $1 \mathrm{a}$ and $1 \mathrm{~b}$ ).

3- Furthermore, we test adults' ability to reason with counterfactual conditionals as well as their ability to keep track of the epistemic status. Based on previous results, and the mental model theory, we predict that adults will show a good ability to make inferences from counterfactual conditionals, as well as a good ability to distinguish the epistemic status.

\section{Method}

\section{Participants}

The sample consisted of fifty-five adults aged between 18 and 27 years $(\mathrm{Mage}=21.25$ years; $\mathrm{SD}=2.29)$. Fifty-two were women and three were men. All participants were native Spanish speakers and were recruited in colleges or universities in Granada.

The sample size was computed based on the epistemic responses of adults from Gómez-Sánchez et al. (2020) previous results. Using $G^{*}$ power, to obtain the same effect (partial eta squared .04, with a power .90) we needed at least, 44 participants. We added one fourth more (11), predicting the loss of participants in one of the analyses that requires complete coherence in their responses to compare frequencies.

Participants read a consent form complying with the University Research Ethics Committee guidelines. The procedure and the task for this study, as well as for Study 2 with children, were also approved by the same committee.

\section{Materials}

Nine stories were created (one of them as a practice trial), based on the materials in Gómez-Sánchez et al. (2020) ${ }^{1}$ and Rafetseder et al. (2013) to test inferential accuracy, epistemic status and identification of the cause of the consequent in counterfactual reasoning. The stories were adapted to test the hypotheses in this study.

Two kinds of story were used depending on the kind of counterexample (alternative or disabler). In the disabler stories such as (3), the presence of the action mentioned in the antecedent (pouring water into a bucket) does not produce any consequence (the bucket stays empty). To infer that the correct answer is empty people have to remember that the bucket had a hole. In the second kind of story, alternative stories such as (2), the action mentioned in the consequent

\footnotetext{
1 Although the first (inferential) and second (epistemic status) questions in both tasks (Gómez-Sánchez et al., 2020 and the present one) are formulated in the same way and the dependent variables were the same, factors involved in both studies differ. In Gómez-Sánchez et al. (2020) only the type of conditional (semifactual 'even if', counterfactual 'if') was used as independent variable. In the present study, we do not use this variable. Instead, we use counterexamples (alternative, disabler) and concreteness (concrete, abstract). This therefore makes the grammar and even the content of the stories different. In addition, the third question of the present paper is entirely novel, trying to study how the counterfactual possibility is constructed.
} 
Fig. 1 (continued)

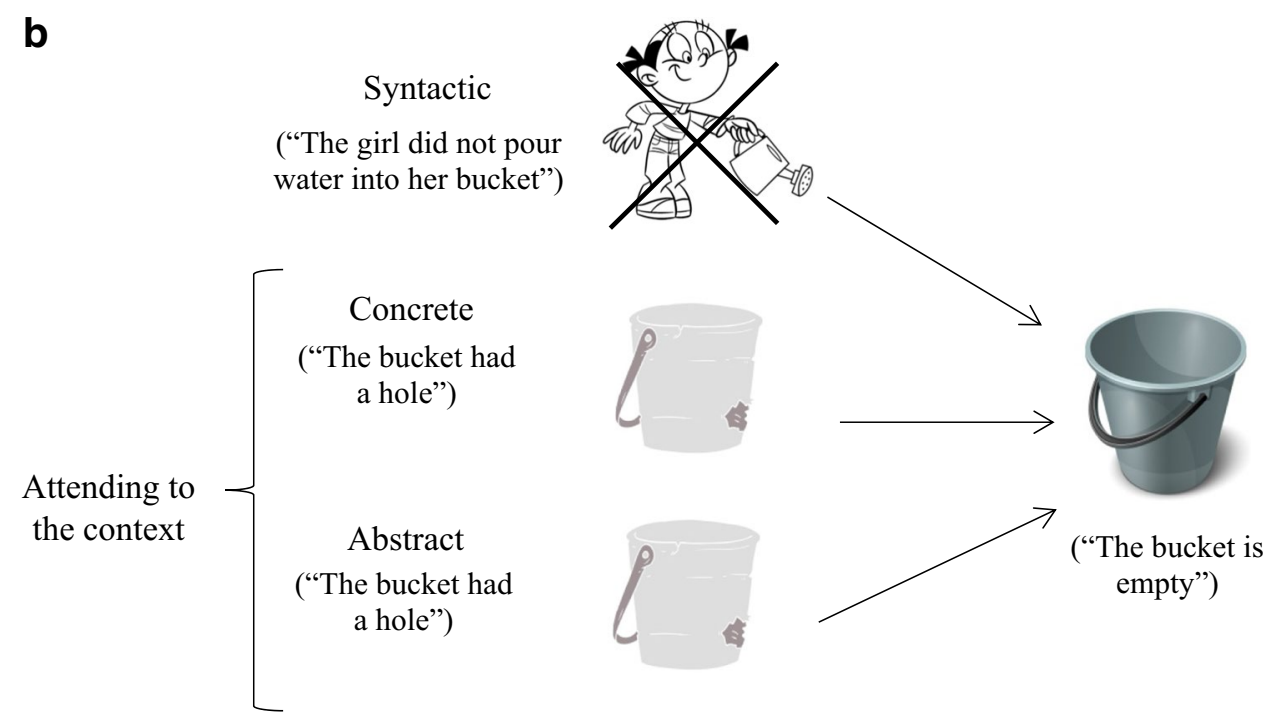

happens (the child is awake), even though the antecedent does not happen (the sister does not make noise). This happens because a different antecedent (e.g. the alarm clock) causes the same effect (the child is awake).

In addition, we manipulated the concreteness of the action (concrete vs. abstract) in order to test whether providing a concrete action improves accuracy in the alternative condition, without showing differences in the control disabler condition. The difference between both is shown in the example below.

The participants were presented with a questionnaire which started with a short introduction, asking participants to take the role of an investigator, using the information provided by a police officer, and having to infer what happened in each story. After completing a practice trial where one story is presented, participants were presented with the 8 experimental stories ( 4 alternatives and 4 disablers). Each one consisted of three tasks (see an example below):

1. The 'inferential accuracy' task, tests whether when participants are given an antecedent, they conclude the consequent determined by the story should be accepted (e.g. The child was awake; the bucket was empty).

2. The 'epistemic status' task, tests whether they can differentiate real and conjectured situations.

3. The 'causal question' task, tests which cause participants tend to report as being responsible for the outcome mentioned in the story (consequent).

The following is an example of an alternative story (translated from the original Spanish). The manipulation of the concreteness can be seen in bold for the concrete situation and in brackets for the (abstract situation).
The police officer saw through a window of the room that a child was awake because his alarm clock had just sounded (he had trouble sleeping). His sister went into his bedroom to take a toy. Later, the police officer said: 'If his sister had entered silently...'

1. Inferential Question: Would the child have been ... awake(correct) or asleep?

2. Epistemic Status Question: Remember, the police officer said: 'If his sister had entered silently ...' According to this evidence, did the police officer see that his sister went in silently? Yes / No(correct)

3. Causal question: The police officer believes the child was awake because...

The following is an example of a disabler story (translated from the original Spanish). The manipulation of the concreteness can again be seen in bold for the concrete situation and in brackets for the (abstract situation). In this kind of story, as the concreteness is not related to the information needed to answer the questions and, consequently, the concreteness of the cause remains constant, we do not expect differences.

The police officer saw that a girl was on the beach playing with a bucket. Her bucket was broken and had a hole in the bottom. The girl was picking white stones up (occupied). Later, the police officer said: 'If the girl had poured water into her bucket...'

1. Inferential Question: Would the bucket have been...full or empty(correct)?

2. Epistemic Status question: Remember, the police officer said: 'If the girl had poured water into her bucket...' According to this evidence, did the police officer see the girl pour water into the bucket? Yes / No(correct) 
3. Causal question: The police officer believes the bucket was empty because...

\section{Procedure and Design}

The participants were tested in small groups (4 people) in a quiet room in a session that lasted 15 minutes. The experimenter read the stories and the conditional statement out loud and asked the participants the inferential accuracy question, the epistemic status question and, finally, the causal question, in that order. Participants had to mark their response on an answer sheet. In the first (inferential) question, they had to choose between the alternatives proposed (e.g. awake or asleep), in the second (epistemic) question they had to think about what actually happened, answering yes or no, and in the third one (causal question) they had to write down what caused the result (e.g. why was the child awake).

Responses to the causal question were coded according to which cause was reported as responsible for the consequent. Hence, responses were classified as syntactic negation of the antecedent (she did not enter silently), predicted cause (the alternative or the disabler), or other causes not presented in the story, such as inventions.

We employed an experimental design with Counterexample (alternative vs. disabler) and Concreteness (concrete vs. abstract) as within-participants variables in all the questions. Concreteness in stories was counterbalanced, this way there were two versions of each alternative/disabler story: one concrete and one abstract. The presentation order of the eight stories was also randomised. As a result, four different workbooks with the mentioned factors were constructed, with every participant receiving one. The dependent variables were inferential accuracy, epistemic status accuracy and frequency of the predicted cause.

\section{Results}

\section{Inferential Response}

As can be seen in Table 1, adults showed a correct counterfactual understanding, with a mean of $92 \%$ correct responses. Moreover, there was no difference between alternatives and disablers (91\% vs. 93\%) nor between concrete and abstract negation (both $92 \%$ ).

We carried out a Wilcoxon rank-test in Counterexample (alternative vs. disabler) and Concreteness (concrete vs. abstract) as independent variables and Inferential accuracy as dependent variable. The results showed no
Table 1 Percentages of correct responses in Inferential response and Epistemic status, means and standard deviations in brackets for Counterexample (alternative, disabler) and Concreteness (concrete, abstract) in Study 1

\begin{tabular}{lllll}
\hline & & Alternative & Disabler & $M$ \\
\hline Inferential response & Concrete & $90(.22)$ & $93(.18)$ & $92(.20)$ \\
& Abstract & $92(.19)$ & $92(.19)$ & $92(.19)$ \\
& $\mathrm{M}$ & $91(.21)$ & $92(.19)$ & \\
Epistemic status & Concrete & $82(.29)$ & $79(.27)$ & $80(.28)$ \\
& Abstract & $71(.38)$ & $77(.32)$ & $74(.35)$ \\
& $\mathrm{M}$ & $76(.34)$ & $78(.29)$ & \\
\hline
\end{tabular}

differences depending on the kind of counterexample $(Z=$ $.52, p=.60)$ nor on the concreteness $(Z=.22, p=.826)$.

\section{Epistemic Status}

As can be seen in Table 1, the epistemic status difficulty (77\% correct responses) contrasted with the inferential accuracy previously referred to (92\% correct responses). A second Wilcoxon rank-test analysis was carried out to examine performance on the epistemic status question. As in the inferential response, there was no difference between alternatives and disablers (76\% vs. $78 \%, Z=.41, p=.685)$ nor between concrete and abstract negation $(80 \%$ vs. $74 \%$, $Z=1.39, p=.165)$.

\section{Causal Question}

We categorised the responses to the causal questions as referring to the syntactic negation of the antecedent (e.g. the girl did not pour water; the sister did not enter silently, etc.), referring to the actual cause referred to in the story (e.g. the bucket had a hole, the alarm clock sounded, he had trouble sleeping, etc.), and finally other different causes not present in the story, such as inventions. We excluded participants who responded inconsistently across the two scenarios they were given for each condition. The number of remaining participants in the alternative concrete condition was 30 (25 selected the predicted cause and 5 the syntactic negation of the antecedent), 35 in the alternative abstract condition (27 predicted cause, 7 negation of the antecedent and 1 other causes), 40 in the disabler concrete condition (34 predicted cause and 6 negation of the antecedent) and finally 37 in the disabler abstract condition (31 predicted cause and 6 negation of the antecedent).

As can be seen in Table 2, the predicted cause was the most designated cause $(70 \%)$ regardless of its concreteness in both types of counterexamples.

Four chi-square tests were performed to examine whether adults provided as cause of the consequent ("why the boy was awake"; "why the bucket was empty") either negations 
Table 2 Percentages of causes of the consequent reported (negation of the antecedent, predicted cause and others), means and standard deviations in brackets for Counterexample (alternative, disabler) and Concreteness (concrete, abstract) in Study 1

\begin{tabular}{|c|c|c|c|c|c|}
\hline & \multirow{2}{*}{$\begin{array}{l}\text { Alternative } \\
\text { Concrete }\end{array}$} & \multicolumn{3}{|l|}{ Disabler (Control) } & \multirow[b]{2}{*}{$M$} \\
\hline & & Abstract & Concrete & Abstract & \\
\hline Predicted cause & $\begin{array}{l}65(.35) \\
\text { 'Alarm clock' }\end{array}$ & $\begin{array}{l}67(.37) \\
\text { 'Trouble sleeping' }\end{array}$ & $\begin{array}{l}74(.36) \\
\text { 'Hole' }\end{array}$ & $\begin{array}{l}72(.36) \\
\text { 'Hole' }\end{array}$ & $70(.36)$ \\
\hline Negation of the antecedent & $\begin{array}{l}24(.34) \\
\text { 'Did not enter silently' }\end{array}$ & $\begin{array}{l}28(.36) \\
\text { 'Did not enter silently' }\end{array}$ & $\begin{array}{l}24(.35) \\
\text { 'Did not pour water' }\end{array}$ & $\begin{array}{l}23(.35) \\
\text { 'Did not pour water' }\end{array}$ & $25(.35)$ \\
\hline Others & $11(.21)$ & $5(.15)$ & $2(.10)$ & $5(.15)$ & $5(.15)$ \\
\hline
\end{tabular}

of the antecedent ("the sister did not enter silently"; "the girl did not pour water") or predicted causes ("the bucket had a hole"; "the alarm clock sounded", etc.). The chi-square tests showed adults more frequently referred to the predicted cause as the cause of the consequent than the syntactic negation of the antecedent: alternative stories with a concrete situation $\left(X^{2}(1,30)=13.33, p<.001\right)$, alternative stories with an abstract situation $\left(X^{2}(2,35)=31.77, p<.001\right)$, disabler stories with a concrete situation $\left(X^{2}(1,40)=19.60\right.$, $p<.001)$, and disabler stories with an abstract situation $\left(X^{2}\right.$ $(1,37)=16.89, p<.001)$.

We also carried out a third Wilcoxon rank-test with Counterexample (alternative vs. disabler) and Concreteness (concrete vs. abstract), with the frequency of the predicted cause (e.g. the bucket had a hole; alarm clock; trouble sleeping) as dependent variable. The results showed an effect of Counterexample with participants identifying more predicted causes in disabler than in alternative stories $(73 \%$ vs. $66 \% ; Z=$ $2.03, p=.042, \mathrm{r}=.22)$. However, we did not find effect of Concreteness $(Z=.144, p=.885)$.

\section{Discussion}

The results show that adults have good counterfactual thinking abilities (92\% accuracy). As was expected, their ability to answer questions about epistemic status was not as good (75\% accuracy). Consistent with previous findings, it seems that people can lose track of the footnotes (e.g. GómezSánchez et al., 2020; Ruiz-Ballesteros \& Moreno-Ríos, 2017). Accuracy decreases because these mental footnotes are required to distinguish real and conjectured possibilities. However, when people make an inference given the antecedent, they accept the consequent without problem, because they do not need to recover their footnotes (which situation is the real one and which the conjectured one).

The most novel result was the one that concerns how adults construct the negation of the antecedent in order to think with counterfactuals. As far as we know it is something that has not been studied before. Results support our hypothesis in adults, in that they more frequently report the predicted cause (the alternative or the disabler) as the cause of the consequent than the syntactic negation of the antecedent (using "not"). The effect is found with both kinds of counterexamples. It means that adults construct the negation of the antecedent by thinking of the alternative and affirmative situation (e.g. alarm clock, hole in the bucket) instead of by recovering the syntactic negation of the antecedent (she did not enter silently; she did not pour water).

\section{Study 2 - Children}

In the second study we tested children with the same task as adults. The aim of this study was to establish a developmental view of the findings with adults in Study 1. Hence, we evaluated the development of counterfactual thinking, as well as of the ability to keep track of epistemic status. Moreover, we tested how children construct the counterfactual possibility, as we did with adults. We therefore expect that children will recover the predicted cause (the alternative or the disabler) as the cause of the consequent more than the syntactic negation of the antecedent using propositional symbols ("not").

Considering the increase with age in the ability to create alternatives (Barrouillet et al., 2009; Santamaría et al., 2013), as well as in working memory efficiency (Beck et al., 2009; Drayton et al., 2011; Ferguson \& Cane, 2015; Gathercole et al., 2004), we predict a developmental trend in the ability to think counterfactually, as well as in the ability to distinguish the epistemic status (real and conjectured situation). The mental model theory maintains that one source of error when inferring is the easy loss of labels in the mental models, particularly in load conditions of working memory (Johnson-Laird, 1983; Johnson-Laird \& Byrne, 2002). The limitation in younger children's working memory span could led them to use an economical representation of counterfactuals by omitting the epistemic labels. Therefore, we predict more errors detecting the epistemic status than thinking counterfactually because children lose the mental footnotes about which situation is the real one and which the conjectured one. 
Furthermore, if children represent negation by thinking about another possibility instead of negating the antecedent as adults do (Espino \& Byrne, 2018; Study 1), and they are not able to think about negation in an abstract way, as some studies propose, then we predict the same effect we found with adults: to recover as the cause of the consequent to a lesser extent the syntactic negation of the antecedent compared to the predicted cause.

Finally, by manipulating concreteness (concrete vs. abstract situation) we predict that children will report the abstract situation as the cause of the consequent to a lesser extent than the concrete situation in alternatives stories but not in control disabler stories. This prediction is based on the findings about the construction of negation using concrete cases in schoolchildren and the development of the ability to create abstract negation in adolescence and adulthood (Markovits, 2013; Markovits \& Lortie-Forgues, 2011). When we ask about the cause of an event in alternative stories (e.g. the boy was awake because...), children should find it easier to recover a concrete and imaginable situation or cause (the alarm clock) rather than an abstract one (trouble sleeping; see Figure 1a) to explain why the boy was awake, due to their poor ability to think about abstract negation. However, we do not predict any differences with disablers because, as we said before, they act as control.

\section{Method}

\section{Participants}

One hundred and forty-three children aged between 8 and 12 years $\left(M_{\text {age }}=10.33 ; S D\right.$ 1.15) from three schools in Granada participated in this study. There were 53 girls with a mean age of 10.44 years $(S D=1.19)$ and 90 boys with a mean age of 10.26 years $(S D=1.13)$. They were organised into their two year groups: $2^{\text {nd }}$ (73 children; $M_{\text {age }}=9.35$; Age range: 8.00-10.22) and $3^{\text {rd }}$ (70 children; $M_{a g e}=11.35$; Age range: 10.34-12.95). All participants spoke Spanish as their first language.

The sample size was computed using $\mathrm{G}^{*}$ power based on the responses of children from Gómez-Sánchez et al. (2020) previous results. We used the same strategy as in Study 1 but looking at differences in the interaction Conditional (even if, if) with Age-group in the epistemic measure found in Gómez-Sánchez et al. (2020). In this case the minimum sample size required (partial eta squared .02 to get a power of .90) was 108 participants. For the same reason than in Experiment 1, and predicting that children could be less coherent than adults in their responses, in order to make the test of frequencies only in participants with complete coherent responses we increased the sample in a third (35).

They participated in the study only if their parents gave written consent, complying with the ethical protocol from the University Ethics Committee for this study.

\section{Materials}

We used the same counterfactual reasoning task employed in Study 1(adults).

\section{Procedure and Design}

We manipulated the same factors within-participants as in Study 1 with adults: Counterexample (disabler vs. alternative), Concreteness (concrete vs. abstract) and Cause (negation vs. predicted cause). We added a fourth between-participants variable: Year group (2 vs. 3).

The task was carried following the same procedure as in Study 1.

\section{Results}

\section{Inferential Response}

We carried out a Wilcoxon test with counterexample (alternative vs. disabler) and concreteness (concrete vs. abstract), and a Mann Whitney U test with year group $\left(2^{\text {nd }}\right.$ vs. $\left.3^{\text {rd }}\right)$ with inferential accuracy as dependent variable. Consistent with our hypothesis, the results showed an effect of year group (78\% vs. $87 \% ; Z=2.77, p=.006$, $\mathrm{r}=.23$ ), revealing a developmental trend in the ability to reason with counterfactual conditionals. They also showed an effect of counterexamples with more correct responses in disabler than in alternative stories $(85 \%$ vs. $79 \% ; Z=$ $2.87, p=.004, \mathrm{r}=.17)$. We did not find an effect in concreteness $(Z=.63, p=.526)($ Table 3$)$.

\section{Epistemic Status}

For the epistemic status question, we carried out a Wilcoxon rank-test for counterexample (alternative vs. disabler) and concreteness (concrete vs. abstract), as well as a Mann Whitney U test in order to compare year group $\left(2^{\text {nd }}\right.$ vs $\left.3^{\text {rd }}\right)$, using Epistemic status as dependent variable.

The results showed an effect of year group $(60 \%$ vs. $70 \%$; $Z=2.52, p=.012, \mathrm{r}=.21$ ), showing a developmental trend in the ability to distinguish real and conjectured situations. However, we did not find any other effects (counterexample: $Z=1.16, p=.248$; concreteness: $Z=1.44, p=.151)$. 
Table 3 Percentages of correct responses in Inferential response and Epistemic status, means and standard deviations in brackets by year group, counterexample (alternative, disabler) and concreteness (concrete, abstract) in Study 2

\begin{tabular}{llllll}
\hline & & Alternative & \multicolumn{3}{l}{ Disabler } \\
\hline & Year group & Concrete & Abstract & Concrete & Abstract \\
Inferential & $2^{\text {nd }}$ & $78(.32)$ & $71(.35)$ & $79(.31)$ & $83(.25)$ \\
response & $3^{\text {rd }}$ & $84(.28)$ & $83(.28)$ & $90(.20)$ & $89(.22)$ \\
Epistemic & $2^{\text {nd }}$ & $62(.35)$ & $60(.34)$ & $61(.37)$ & $58(.34)$ \\
status & $3^{\text {rd }}$ & $67(.32)$ & $65(.34)$ & $77(.29)$ & $69(.33)$ \\
\hline
\end{tabular}

\section{Causal Question}

We categorised responses and participants as in Study 1. The number of remaining participants in the alternative concrete condition was 90 (81 in the predicted cause, 6 in the syntactic negation of the antecedent and 3 in the other causes), 56 in the alternative abstract condition ( 47 predicted cause, 7 negation of the antecedent and 2 other causes), 99 in the disabler concrete condition ( 92 predicted cause, 4 negation of the antecedent and 3 other causes) and finally 105 in the disabler abstract condition (98 predicted cause, 5 negation of the antecedent and 2 other causes). The total number of excluded participants was similar in both year groups: in the case of alternatives, 70 from the $2^{\text {nd }}$ year group and 69 for the $3^{\text {rd }}$ year group; in the case of disablers 44 in the $2^{\text {nd }}$ year group and 37 in the $3^{\text {rd }}$ year group.

A chi-square test was carried out to test whether children provided as cause of the consequent (why the boy was awake; why the bucket was empty) either more negations of the antecedent ("the sister did not enter silently"; "the girl did not pour water") or predicted causes ("the bucket had a hole"; "the alarm clock sounded"; "the child had trouble sleeping", etc.). The chi-square test showed children more frequently suggested the predicted cause as the cause of the consequent than the negation of the antecedent in all cases: alternative stories with a concrete situation $\left(X^{2}\right.$ $(3,90)=120.36, p<.001)$, alternative stories with an abstract situation $\left(X^{2}(3,56)=131.99, p<.001\right)$, disabler stories with a concrete situation $\left(X^{2}(3,99)=148.61, p<.001\right)$, and disabler stories with an abstract situation $\left(X^{2}(3,105)=166.85, p<.001\right)$.
We also carried out a third Wilcoxon rank-test analysis using counterexample (alternative vs. disabler) and concreteness (concrete vs. abstract), and Mann Whitney U test for year group $\left(2^{\text {nd }}\right.$ vs. $\left.3^{\text {rd }}\right)$, with the frequency of the predicted cause (e.g. the bucket had a hole; alarm clock; trouble sleeping) as dependent variable.

Results showed an effect of counterexample, giving more predicted responses with disablers than with alternatives $(80 \%$ vs. $66 \% ; Z=5.27, p<.001, \mathrm{r}=.31)$. There was a main effect of concreteness with more predicted causes when the situation was concrete (alarm clock) compared to abstract (trouble sleeping; $76 \%$ vs. $70 \% ; Z=2.29, p=.022, \mathrm{r}=.14$ ). However, we did not find an effect of year group ( $70 \%$ vs. $75 \% ; Z=1.49$, $p=.137)$. As expected, there was no effect of concreteness in disablers $(Z=.64, p=.52)$ but there was in alternatives, giving more predicted causes with concrete situations than with abstract $(73 \%$ vs. $58 \%, Z=3.56, p<.001, \mathrm{r}=.21)($ Table 4$)$.

In order to compare the performance of children and adults, we carried out an additional analysis using the Mann Whitney U test. We must be cautious with the interpretation of this analysis because, although we used the same task, the experiments were made at different time and places.

In the first question (inferential response), the analysis showed more correct responses in adults than in children $(Z$ $=3.71, p<.001, \mathrm{r}=.26)$. The same occurred in the second question on epistemic status $(Z=3.73, p<.001, \mathrm{r}=.27)$, but there was no difference in the third one $(Z=.06, p=$ .953). Moreover, as was expected and as has been seen previously, children found it easier to recover concrete causes in alternatives $(73 \%$ vs. $58 \%, Z=3.56, p<.001, \mathrm{r}=.21)$ but not in disablers $(Z=.64, p=.52)$. Adults did not show such difference in either condition (alternatives: $Z=.19, p$ $=.853$; disablers: $Z=.47, p=.637$ ).

\section{General Discussion}

In the present studies, we examined the development of counterfactual reasoning and the ability to distinguish real and conjectured situations, as well as the ability to keep
Table 4 Percentages of causes of the consequent reported (negation of the antecedent, predicted cause and others), means and standard deviations in brackets by counterexample (alternative, disabler) concreteness (concrete, abstract) and year group $\left(2^{\text {nd }}\right.$ vs $\left.3^{\text {rd }}\right)$ in Study 2

\begin{tabular}{llllllll}
\hline & & \multicolumn{2}{l}{ Alternative } & & \multicolumn{2}{l}{ Disabler } & \\
& & Concrete & Abstract & & Concrete & Abstract & $M$ \\
\hline $2^{\text {nd }}$ & Predicted cause & $70(.35)$ & $56(.33)$ & & $77(.31)$ & $78(.33)$ & $70(.33)$ \\
& Negation of the antecedent & $18(.28)$ & $24(.31)$ & & $14(.27)$ & $12(.26)$ & $17(.28)$ \\
& Others & $12(.26)$ & $20(.27)$ & $9(.23)$ & $10(.22)$ & $13(.25)$ \\
$3^{\text {rd }}$ & Predicted cause & $75(.34)$ & $61(.33)$ & & $82(.28)$ & $84(.28)$ & $75(.31)$ \\
& Negation of the antecedent & $19(.28)$ & $21(.28)$ & & $10(.22)$ & $14(.26)$ & $16(.26)$ \\
& Others & $6(.17)$ & $18(.24)$ & & $8(.20)$ & $2(.13)$ & $9(.19)$ \\
\hline
\end{tabular}

Note: see Table 2 to know what responses were computed in each case. 
track of them (epistemic status). Counterfactual reasoning requires negating the antecedent to create the counterfactual possibility, however as far as we are aware it is not known how adults and children think about negation in order to negate the antecedent, and this was our most important aim.

As expected, we found high accuracy (92\%) in adults' ability to make inferences from counterfactual statements. As predicted, children's performance showed a developmental trend in this ability (78\% in 8-10 years old children and $87 \%$ in $10-12$ years old children), that could be due to an increase in the ability to consider alternatives and increases in working memory capacity. This finding is consistent with results from earlier studies that indicate that 6 to 7 yearolds can indeed reason counterfactually (McCormack et al., 2018; Nyhout et al., 2019; Rafetseder \& Perner, 2018), but revealing counterfactual thinking as a developmental ability, that improves until adolescence (Gómez-Sánchez et al., 2020; Rafetseder et al., 2013, 2021).

Regarding the epistemic status, we found that adults showed more difficulty than in the inferential task with a mean of $77 \%$ correct responses. This finding is consistent with previous results (Gómez-Sánchez et al., 2020; RuizBallesteros \& Moreno-Ríos, 2017; Thompson \& Byrne, 2002). According to the mental model theory, responding correctly to the epistemic status question requires not only having a complete representation of counterfactuals that includes the conjectured and the presupposed model, but also keeping in mind their labels in order to keep track of their epistemic status. These labels or mental footnotes are easily forgotten (Johnson-Laird, 1983; Johnson-Laird \& Byrne, 2002), causing a decrease in the number of correct responses. Children's performance on the epistemic status questions also showed a developmental trend (60\% vs. $70 \%$ ) and as with the adult group, their performance was worse than on the inferential task. In a previous study, GómezSánchez et al. (2020), using similar stories (with some important differences regarding the variables manipulated here, such as concreteness and counterexample availability), also found higher scores in the inference responses than in the epistemic status and a developmental improvement with age in the epistemic responses. This ability could be crucial for achieving correct counterfactual reasoning (GómezSánchez et al., 2020).

Finally, in respect of the causal question, we found the expected effect. More predicted causes were reported (e.g. the bucket had a hole, the child had trouble sleeping, etc.) as being the cause of the consequent than the syntactic negation of the antecedent using propositional symbols (e.g. the girl did not pour water; the sister did not enter silently, etc.). We observed this effect in both studies, which implies that adults and children construct the counterfactual possibility in the same way. These results are consistent with previous research, showing that people construct negation ("there is not a light figure") by recovering another possibility ("a dark figure") instead of by thinking on the syntactic negation ("not light figure") (Espino \& Byrne, 2018; Khemlani et al., 2012; Mayo et al., 2004; Moreno-Ríos \& Byrne, 2018). The inference-to-alternative effect (Espino \& Byrne) was obtained only with binary possibilities but not with nonbinary possibilities (there is a red figure). In our study, the alternative stories contain two possible causes. As with the binary categories, the negation of one, seems to lead people to think of the other. It is possible that effect could disappear with more possible causes.

Something that was not expected was observing more predicted causes in disablers than in alternatives stories, especially as we found this effect in both studies. Although both kinds of stories are not comparable as they are different, it could be related to the salience of the cause: in alternatives the cause is something (e.g. an alarm clock; trouble sleeping) that does not get as much attention as in the disabler stories, where something unusual happened (e.g. a bucket with a hole). It could also be related to the structure of the counterexample. In disabler stories there is no competing alternative that catches attention, whereas in the alternative stories an explicit alternative is mentioned. However, more research is needed in order to find what causes this result.

We also found that children, unlike adults, gave the predicted cause more with concrete situations than with abstract situations, which could be explained by their poor ability in thinking with abstract concepts. Moreover, as hypothesized, the manipulation of concreteness had an impact on alternative stories but not in control disabler stories. This happens because alternative stories provide an explicit situation that corresponds to the negation of the antecedent, and the manipulation of its concreteness affected the recovery of the cause, as expected. In other words, when we asked children why the child was awake they reported the predicted response with concrete situations ("because the alarm clock sounded") more than with abstract situations ("because he had trouble sleeping"). However, this effect was not found in disabler stories because they acted as control, with the concreteness of the cause remaining constant (compare Figures $1 \mathrm{a}$ and $1 \mathrm{~b}$ ). This result is in accordance with the developmental differences in their ability to negate, as schoolchildren find difficulty in thinking abstractly (Markovits, 2013; Markovits \& Lortie-Forgues, 2011).

The findings of the present studies bring to light several difficulties that could cause children's difficulty in thinking with counterfactuals, such as keeping in mind which is the real situation and which the conjectured one, and having to negate the antecedent in an abstract way. However, the most novel result is the one related to how adults and children construct negation. More research is needed in order to know to what extent these difficulties are responsible for their performance in counterfactual thinking and whether the 
construction of negation of the antecedent can be generalised to other kind of contents.

Availability of Data and Material The data for both experiments are available at https://osf.io/y4p3w/?view_only=e6e7ae4d56a4469183b8 ae84628023b3

\section{Authors' Contributions Conceptualization: JG, SM, CF \\ Formal analysis: JG, SM \\ Funding acquisition: JG, SM \\ Investigation: JG \\ Methodology: JG, SM, CF \\ Writing - original draft: JG \\ Writing - review \& editing: JG, SM, CF}

Funding Information Funding for open access charge: Universidad de Granada / CBUA This research was funded by grants from the Spanish Government, Ministry of Economy and Competitiveness (PGC2018095868-B-I00) to SM and the Education, Culture and Sport Ministry (FPU15/05899) to JG.

\section{Declarations}

Conflicts of Interest/Competing Interests The authors have declared that no competing interests exist.

Code Availability Not aplicable

Ethics Approval The study was approved by the university's ethical review board (Comité de Ética en Investigación Humana de la Universidad de Granada: 1068/CEIH/2020)

Consent to Participate and for Publication Informed consent was obtained from all individual participants included in the study 1 .

Written informed consent was obtained from the parents in the study 2 .

Open Access This article is licensed under a Creative Commons Attribution 4.0 International License, which permits use, sharing, adaptation, distribution and reproduction in any medium or format, as long as you give appropriate credit to the original author(s) and the source, provide a link to the Creative Commons licence, and indicate if changes were made. The images or other third party material in this article are included in the article's Creative Commons licence, unless indicated otherwise in a credit line to the material. If material is not included in the article's Creative Commons licence and your intended use is not permitted by statutory regulation or exceeds the permitted use, you will need to obtain permission directly from the copyright holder. To view a copy of this licence, visit http://creativecommons.org/licenses/by/4.0/.

\section{References}

Barrouillet, P., Gavens, N., Vergauwe, E., Gaillard, V., \& Camos, V. (2009). Working Memory Span Development: A Time-Based Resource-Sharing Model Account. Developmental Psychology, 45(2), 477-490. https://doi.org/10.1037/a0014615

Beck, S. R., \& Riggs, K. J. (2014). Developing thoughts about what might have been. Child Development Perspectives, 8(3), 175179. https://doi.org/10.1111/cdep.12082

Beck, S. R., Riggs, K. J., \& Gorniak, S. L. (2009). Relating developments in children's counterfactual thinking and executive functions. Thinking and Reasoning, 15(4), 337-354. https:// doi.org/10.1080/13546780903135904

Bucciarelli, M., \& Johnson-Laird, P. N. (2005). Naïve deontics: A theory of meaning, representation, and reasoning. Cognitive Psychology, 50(2), 159-193. https://doi.org/10.1016/j.cogps ych.2004.08.001

Buchsbaum, D., Bridgers, S., Weisberg, D. S., \& Gopnik, A. (2012). The power of possibility: Causal learning, counterfactual reasoning, and pretend play. Philosophical Transactions of the Royal Society B: Biological Sciences, 367(1599), 2202-2212. https://doi.org/10.1098/rstb.2012.0122

Byrne, R. M. J. (2016). Counterfactual Thought. Annual Review of Psychology, 67(1), 135-157. https://doi.org/10.1146/annur ev-psych-122414-033249

Byrne, R. M. J., \& Johnson-Laird, P. N. (2009). "If" and the problems of conditional reasoning. Trends in Cognitive Sciences, 13(7), 282-287. https://doi.org/10.1016/j.tics.2009.04.003

Byrne, R. M. J. (2017). Counterfactual Thinking: From Logic to Morality. Current Directions in Psychological Science, 26(4), 314-322. https://doi.org/10.1177/0963721417695617

Cummins, D. D. (1995). Naive theories and causal deduction. Memory \& Cognition, 23(5), 646-658. https://doi.org/10.3758/BF031 97265

De Neys, W., \& Everaerts, D. (2008). Developmental trends in everyday conditional reasoning: The retrieval and inhibition interplay. Journal of Experimental Child Psychology. https://doi.org/10. 1016/j.jecp.2008.03.003

Drayton, S., Turley-Ames, K. J., \& Guajardo, N. R. (2011). Counterfactual thinking and false belief: The role of executive function. Journal of Experimental Child Psychology, 108(3), 532-548. https://doi.org/10.1016/j.jecp.2010.09.007

Espino, O., \& Byrne, R. M. J. (2018). Thinking About the Opposite of What Is Said: Counterfactual Conditionals and Symbolic or Alternate Simulations of Negation. Cognitive Science, 42(8), 2459-2501. https://doi.org/10.1111/cogs.12677

Faul, F., Erdfelder, E., Lang, A. G., \& Buchner, A. (2007). G* Power 3: A flexible statistical power analysis program for the social, behavioral, and biomedical sciences. Behavior research methods, 39(2), 175-191.

Ferguson, H. J., \& Cane, J. E. (2015). Examining the cognitive costs of counterfactual language comprehension: Evidence from ERPS. Brain Research, 1622, 252-269. https://doi.org/10.1017/CBO97 81107415324.004

Gathercole, S. E., Pickering, S. J., Ambridge, B., \& Wearing, H. (2004). The Structure of Working Memory from 4 to 15 Years of Age. Developmental Psychology, 40(2), 177-190. https://doi.org/ 10.1037/0012-1649.40.2.177

Gómez-Sánchez, J., Ruiz-Ballesteros, J. A., \& Moreno-Ríos, S. (2020). How children and adults keep track of real information when thinking counterfactually. PLOS ONE, 15(12), e0242967. https:// doi.org/10.1371/journal.pone.0242967

Guajardo, N. R., Parker, J., \& Turley-Ames, K. (2009). Associations among false belief understanding, counterfactual reasoning, and executive function. British Journal of Developmental Psychology, 27(3), 681-702. https://doi.org/10.1348/026151008X 357886

Johnson-Laird, P. N. (1983). Mental models. Oxford University Press. Johnson-Laird, P. N. (2006). How We Reason. Oxford University Press. Johnson-Laird, P. N., \& Byrne, R. M. J. (1991). Deduction. Erlbaum.

Johnson-Laird, P. N., \& Byrne, R. M. J. (2002). Conditionals: A theory of meaning, pragmatics, and inference. Psychological Review, 109(4), 646-678. https://doi.org/10.1037/0033-295X.109.4.646

Khemlani, S., Orenes, I., \& Johnson-Laird, P. N. (2012). Negation: A theory of its meaning, representation, and use. Journal of Cognitive Psychology, 24(5), 541-559. https://doi.org/10.1080/20445 911.2012 .660913 
Khemlani, S., Orenes, I., \& Johnson-Laird, P. N. (2014). The negations of conjunctions, conditionals, and disjunctions. Acta Psychologica, 151, 1-7. https://doi.org/10.1016/j.actpsy.2014.05.004

Markovits, H. (2013). The development of abstract conditional reasoning. In P. Barrouillet \& C. Gauffroy (Eds.), The development of abstract conditional reasoning (pp. 71-92). Psychology Press.

Markovits, H., \& Lortie-Forgues, H. (2011). Conditional Reasoning With False Premises Facilitates the Transition Between Familiar and Abstract Reasoning. Child Development, 82(2), 646-660. https://doi.org/10.1111/j.1467-8624.2010.01526.x

Mayo, R., Schul, Y., \& Burnstein, E. (2004). "I am not guilty" vs "I am innocent": Successful negation may depend on the schema used for its encoding. Journal of Experimental Social Psychology, 40(4), 433-449. https://doi.org/10.1016/j.jesp.2003.07.008

McCormack, T., Ho, M., Gribben, C., O'Connor, E., \& Hoerl, C. (2018). The development of counterfactual reasoning about doubly-determined events. Cognitive Development, 45, 1-9. https:// doi.org/10.1016/j.cogdev.2017.10.001

Moreno-Ríos, S., \& Byrne, R. M. J. (2018). Inferences from disclosures about the truth and falsity of expert testimony. Thinking and Reasoning, 24(1), 41-78. https://doi.org/10.1080/13546783.2017.1378724

Moreno-Rios, S., \& García-Madruga, J. A. (2002). El desarrollo del razonamiento sobre lo que podría haber ocurrido: condicionales indicativos y subjuntivos. Infancia y Aprendizaje, 25(3), 485-498.

Nyhout, A., \& Ganea, P. A. (2019). Mature counterfactual reasoning in 4- and 5-year-olds. Cognition, 183, 57-66. https://doi.org/10. 1016/j.cognition.2018.10.027

Nyhout, A., Henke, L., \& Ganea, P. A. (2019). Children's Counterfactual Reasoning About Causally Overdetermined Events. Child Development, 90(2), 610-622. https://doi.org/10.1111/cdev.12913

Orenes, I., Beltrán, D., \& Santamaría, C. (2014). How negation is understood: Evidence from the visual world paradigm. Journal of Memory and Language, 74, 36-45. https://doi.org/10.1016/j.jml.2014.04.001

Rafetseder, E., Cristi-Vargas, R., \& Perner, J. (2010). Counterfactual reasoning: Developing a sense of "nearest possible world.". Child Development, 81(1), 376-389. https://doi.org/10.1111/j.14678624.2009.01401.x

Rafetseder, E., O'Brien, C., Leahy, B., \& Perner, J. (2021). Extended difficulties with counterfactuals persist in reasoning with false beliefs: Evidence for teleology-in-perspective. Journal of Experimental Child Psychology, 204, 105058. https://doi.org/10.1016/j. jecp.2020.105058

Rafetseder, E., \& Perner, J. (2018). Belief and counterfactuality: A teleological theory of belief attribution. Zeitschrift Fur Psychologie / Journal of Psychology, 226(2), 110-121. https://doi.org/10.1027/ 2151-2604/a000327
Rafetseder, E., Schwitalla, M., \& Perner, J. (2013). Counterfactual reasoning: From childhood to adulthood. Journal of Experimental Child Psychology, 114(3), 389-404. https://doi.org/10.1016/j. jecp.2012.10.010

Rasga, C., Quelhas, A. C., \& Byrne, R. M. J. (2016). Children's reasoning about other's intentions: False-belief and counterfactual conditional inferences. Cognitive Development, 40, 46-59. https:// doi.org/10.1016/j.cogdev.2016.08.007

Roldán-Tapia, M. D., Moreno-Ríos, S., \& Cánovas-López, R. (2017). Thinking about social and nonsocial alternative possibilities in premature preschoolers. Journal of Clinical and Experimental Neuropsychology, 39(8), 725-737. https://doi.org/10.1080/13803 395.2016.1257703

Royzman, E. B., Cassidy, K. W., \& Baron, J. (2003). "I Know, You Know": Epistemic Egocentrism in Children and Adults. Review of General Psychology, 7(1), 38-65. https://doi.org/10.1037/10892680.7.1.38

Ruiz-Ballesteros, J. A., \& Moreno-Ríos, S. (2017). Concessive and semifactual interpretations during reasoning with multiple conditionals. Quarterly Journal of Experimental Psychology, 70(7), 1140-1150. https://doi.org/10.1080/17470218.2016. 1172098

Santamaría, C., Tse, P. P., Moreno-Ríos, S., \& García-Madruga, J. A. (2013). Deductive reasoning and metalogical knowledge in preadolescence: A mental model appraisal. Journal of Cognitive Psychology, 25(2), 192-200. https://doi.org/10.1080/20445911. 2012.743988

Thompson, V. A., \& Byrne, R. M. J. (2002). Reasoning Counterfactually: Making Inferences about Things That Didn't Happen. Journal of Experimental Psychology: Learning Memory and Cognition, 28(6), 1154-1170. https://doi.org/10.1037/0278-7393.28.6. 1154

Vargas, C., Moreno-Rios, S., Castro, C., \& Underwood, G. (2011). Encoding time and signs exposure time in the representation of diagrammatic deontic meanings. Acta Psychologica, 137(1), 106-114. https://doi.org/10.1016/j.actpsy.2011.03.006

Weisberg, D. S., \& Gopnik, A. (2013). Pretense, Counterfactuals, and Bayesian Causal Models: Why What Is Not Real Really Matters. Cognitive Science, 37(7), 1368-1381. https://doi.org/10.1111/ cogs.12069

Publisher's Note Springer Nature remains neutral with regard to jurisdictional claims in published maps and institutional affiliations. 